\title{
Mechanism involved in genistein activation of insulin-like growth factor 1 receptor expression in human breast cancer cells
}

\author{
Wen-Fang Chen ${ }^{1,2 *}$, Quan-Gui Gao ${ }^{1}$ and Man-Sau Wong ${ }^{2,3 *}$ \\ ${ }^{1}$ Department of Physiology, Medical College of Qingdao University, China \\ ${ }^{2}$ Central Laboratory of the Institute of Molecular Technology for Drug Discovery and Synthesis, Department of Applied Biology \\ and Chemical Technology, The Hong Kong Polytechnic University, Hung Hom, Kowloon, Hong Kong SAR, China \\ ${ }^{3}$ State Key Laboratory of Chinese Medicine and Molecular Pharmacology, Shenzhen, 518057, China
}

(Received 20 December 2006 - Revised 30 April 2007 - Accepted 11 May 2007)

Our previous studies have shown that genistein can enhance the insulin-like growth factor (IGF)-1 receptor signalling pathway via an oestrogen receptor (ER) in human breast cancer MCF-7 cells. The present study aims to investigate how genistein regulates IGF-1 receptor expression in human MCF-7 cells. Genistein at $1 \mu \mathrm{M}$ stimulated the growth of MCF-7 cells and this effect could be completely blocked by the IGF-1 receptor antagonist JB-1, suggesting that IGF-1 receptor is essential for mediating the proliferative effects of genistein in MCF-7 cells. Genistein increased IGF-1 receptor promoter activity. This effect could be completely abolished by co-treatment of MCF-7 cells with ICI $182,780\left(10^{-6} \mathrm{M}\right)$. Genistein increased IGF-1 receptor gene expression and this effect could be completely blocked by the IGF-1 receptor antagonist JB-1. Co-treatment of MCF-7 cells with cycloheximide $(5 \mu \mathrm{g} / \mathrm{ml})$ completely blocked the induction of IGF-1 receptor protein and mRNA expression by genistein. The results indicated that the induction of IGF-1 receptor promoter activity by genistein required the action of ER while the stimulatory actions of genistein on IGF-1 receptor expression required the activity of the IGF-1 receptor and de novo protein synthesis. These data provide evidence to support the hypothesis that the inductive effects of genistein on IGF-1 receptor expression require the cross-talk between IGF-1 receptor and the ER-dependent pathways.

Genistein: Oestrogen: Insulin-like growth factor 1 receptor: Oestrogen receptor: Human breast cancer

Genistein, a natural isoflavone phyto-oestrogen present in soyabeans, has a chemical structure similar to that of steroidal oestrogens, and its ability to behave as an oestrogen in various tissues has been widely described ${ }^{1,2}$. Genistein has been found to have significant oestrogenic properties in both in vitro and in vivo studies. Physiological concentrations $\left(10^{-9}-10^{-6} \mathrm{M}\right)$ of genistein stimulate the growth of oestrogen receptor (ER)-positive breast cancer cells ${ }^{3,4}$. In ovariectomised athymic mice implanted with MCF-7 cells, both genistein and soya protein stimulate tumour growth in a dose-dependent fashion ${ }^{5,6}$.

Many studies have revealed the mechanism of the oestrogenic effects of genistein. Genistein binds to the ER and activates a number of oestrogen-responsive genes in vitro ${ }^{7,8}$, although its binding affinity is several-fold weaker than that of $17 \beta$-oestradiol $\left(\mathrm{E}_{2}\right)$. Studies clearly demonstrate the presence of independent but interacting mitogenic pathways in the ER-positive breast cancer cells, including the ER pathway and the insulin-like growth factor (IGF)-1 receptor pathway ${ }^{9}$. Oestrogen-stimulated mitogenesis in the ER-positive human breast cancer cells could be mediated both by the ER signalling pathway and the enhancement of the IGF-1 signalling pathway. $E_{2}$ can induce the expression of several members of the IGF family in human breast cancer cells, including
IGF-1 receptor, IGF-2 receptor, IGF binding proteins, insulin receptor substrate 1 and insulin receptor substrate 2 . The up regulation of these proteins by $E_{2}$ provides the potential mechanisms for its autocrine and paracrine control of breast cancer cell mitogenesis ${ }^{10,11}$. Our previous studies clearly indicated that, apart from the classical ER signalling pathway, the proliferative effects of genistein on the ER-positive human breast cancer MCF-7 cells are also related to the IGF-1 receptor signalling pathway ${ }^{12}$. Genistein mimics the action of $E_{2}$ and causes the induction of IGF-1 receptor and insulin receptor substrate 1 expression in MCF-7 cells in a time-dependent manner. In the present study, our aim was to investigate the detailed mechanism by which genistein activates IGF-1 receptor transcription and expression in human breast cancer MCF-7 cells.

\section{Materials and methods \\ Culture of human breast cancer cell line (MCF-7)}

MCF-7 cells (ATCC no. HTB-22; ATCC, Manassas, VA, USA) were routinely cultured in Dulbecco's modified

Abbreviations: CHX, cycloheximide; DMEM, Dubecco's modified Eagle's medium; E 2 , 17 $\beta$-oestradiol; ER, oestrogen receptor; FBS, fetal bovine serum; GAPDH, glyceraldehyde-3-phosphate dehydrogenase; IGF, insulin-like growth factor; MTT, 3-[4, 5-dimethylthiazol 2-yl] 2, 5-diphenyltetrazolium bromide.

* Corresponding authors: Dr Wen-Fang Chen, fax +852 23649932, email marychhk@yahoo.com and Dr Man-Sau Wong, bcmswong@inet.polyu.edu.hk 
Eagle's medium (DMEM) supplemented with $5 \%$ fetal bovine serum (FBS), penicillin (100 international units $/ \mathrm{ml}$ ) and streptomycin $(100 \mu \mathrm{g} / \mathrm{ml})$ (Invitrogen, Carlsbad, CA, USA) at $37^{\circ} \mathrm{C}$ in a humidified atmosphere of $95 \%$ air and $5 \% \mathrm{CO}_{2}$. Cells were transferred to phenol red-free DMEM supplemented with $1 \%$ charcoal-stripped FBS, penicillin (100 units/ml) and streptomycin $(100 \mu \mathrm{g} / \mathrm{ml})$ by standard methods of trypsinisation, plated in six-well dishes for $5 \mathrm{~d}$ and allowed to replicate to $80 \%$ confluence. Then cells were treated either with genistein $\left(10^{-6} \mathrm{M}\right)$ or $\mathrm{E}_{2}\left(10^{-8} \mathrm{M}\right)$ (Sigma, St Louis, MO, USA) for $48 \mathrm{~h}$. The medium and test compounds were replenished at $24 \mathrm{~h}$. For anti-oestrogen, IGF-1 receptor antagonist JB-1 or cycloheximide $(\mathrm{CHX})$ treatment, $\mathrm{MCF}-7$ cells were exposed to genistein or $E_{2}$ in the presence or absence of ICI 182,780 $\left(10^{-6} \mathrm{M}\right.$; Tocris, Bristol, UK), JB-1 $(1 \mu \mathrm{g} / \mathrm{ml}$; Bachem, Bubendorf, Switzerland) or CHX $\left(10^{-6} \mathrm{M}\right.$; Sigma, St Louis, MO, USA) for $48 \mathrm{~h}$.

\section{Cell proliferation assays}

For the growth study, MCF-7 cells were seeded in ninety-sixwell plates $\left(3 \times 10^{3}\right.$ cells/well $)$ in phenol red-free DMEM supplemented with $1 \%$ charcoal-stripped FBS for $4 \mathrm{~d}$ and then treated with genistein $\left(10^{-6} \mathrm{M}\right)$ or $\mathrm{E}_{2}\left(10^{-8} \mathrm{M}\right)$ with or without ICI 182,780 or JB-1 for $48 \mathrm{~h}$. As an indirect measure of growth, the 3-[4, 5-dimethylthiazol 2-yl] 2, 5-diphenyltetrazolium bromide (MTT) assay was used as described previously ${ }^{13}$. Briefly, the medium was removed and replaced with $100 \mu \mathrm{l}$ tetrazolium (MTT, $5 \mathrm{mg} / \mathrm{ml}$; Sigma) in PBS. The plates were incubated for $4 \mathrm{~h}$ at $37^{\circ} \mathrm{C}$, followed by the addition of $100 \mu \mathrm{l}$ of lysis buffer $(0 \cdot 04 \mathrm{M}-\mathrm{HCl}$ in propan-2-ol). The multi-well plates were shaken for $1 \mathrm{~h}$ and the signals were detected by a microplate reader using a wavelength of $595 \mathrm{~nm}$.

\section{Insulin-like growth factor 1 receptor promoter luciferase} assay

The effect of genistein on IGF-1 receptor promoter activity was studied by transient transfection assays using a genomic DNA fragment extending from nucleotides -2350 to +640 (nucleotide corresponds to the transcription site of rat IGF-1 receptor gene) or promoterless luciferase construct that was kindly provided by Dr Derek LeRoith (Diabetes Branch, Bethesda, MD, USA). MCF-7 cells were seeded in twelvewell plates for $1 \mathrm{~d}$ in DMEM medium supplemented with $5 \%$ FBS. Cells were then transferred to phenol redfree DMEM supplemented with $1 \%$ charcoal-stripped FBS for another $2 \mathrm{~d}$. MCF-7 cells were transfected with $0.8 \mu \mathrm{g}$ of reporter plasmid along with $0.4 \mu \mathrm{g}$ of the control reporter plasmids pRL-TK using the Lipofectamine 2000 reagent according to the manufacturer's instructions (Invitrogen). At $5 \mathrm{~h}$ after transfection, cells were treated with genistein or $\mathrm{E}_{2}$ in the presence or absence of $10^{-6} \mathrm{M}$-ICI 182,780 for another $24 \mathrm{~h}$ and then harvested. Luciferase activity encoded by experimental and internal control plasmid was measured sequentially with the use of a TD-20/20 Luminometer (Turner Design, Sunnyvale, CA, USA) and the Dual-Luciferase Reporter reagents according to the supplier's recommendation (Promega, Madison, WI, USA). The IGF-1 receptor promoter activity was expressed as firefly luciferase values normalised by pRL-TK renilla luciferase values.

Semi-quantitative reverse transcriptase-polymerase chain reaction for insulin-like growth factor 1 receptor expression

Total RNA was isolated from cells by using Trizol reagent according to the standard protocol. Total RNA $(2 \mu \mathrm{g})$ was used to generate cDNA in each sample using SuperScript II RT with oligo(dT) 12-18 primers (Invitrogen). The evaluation of $\mathrm{pS} 2$ and IGF-1 receptor expression was performed by semiquantitative RT-PCR as previously described ${ }^{12}$. PCR amplification was performed on a GeneAmp 9600 PCR system (Perkin Elmer, Foster City, CA, USA). Cycle-response curves for each PCR product had been determined to derive the optimal cycle for each gene candidate. The cycles that were chosen would ensure that the PCR product upon normalisation with the expression of housekeeping gene glyceraldehyde-3-phosphate dehydrogenase (GAPDH) between samples could be compared semi-quantitatively. For IGF-1 receptor and GAPDH, the primers used were $5^{\prime}$-ACTATGCCGGTGTCTGTGTG-3' (IGF-1 receptor forward) and 5'-TGCAAGTTCTGGTTGTCGAG-3' $3^{\prime}$ (IGF-1 receptor reverse), and $5^{\prime}$-ACCACAGTCCATGCCTACAC-3' (GAPDH forward) and $5^{\prime}$ TTCACCACCCTGTTGCTGTA-3' (GAPDH reverse) to yield products of 522 and $422 \mathrm{bp}$, with thirty and twenty PCR cycles, respectively. The PCR products were analysed using agarose gel electrophoresis. Optical densities of ethidium bromide-stained DNA bands were quantified using a luminal imager (Lumi-Imager; Roche Molecular Biochemicals, Mannheim, Germany).

\section{Immunoblotting}

For Western blotting, protein was isolated from cells using Trizol reagent according to the standard protocol. Protein concentrations were analysed by the method of Bradford (BioRad, Hercules, CA, USA) ${ }^{14}$. Equal amount of proteins $(5 \mu \mathrm{g})$ were separated by SDS-PAGE on $10 \%$ reducing gels at a constant voltage $(150 \mathrm{~V})$ for $1 \mathrm{~h}$ as previously described ${ }^{15}$, and transblotted onto polyvinylidene difluoride (PVDF) membranes (Immobilin-P; Millipore Corp., Beverly, MA, USA). Immunodetection was performed after blocking non-specific binding sites on the membrane with $5 \%$ skimmed milk. The blots were probed with polyclonal rabbit anti-human IGF-1 receptor $\beta$ (1:2000; Santa Cruz Biotechnology, Inc., Santa Cruz, CA, USA) as the primary antibody, followed by incubation with the goat anti-rabbit antibody conjugated with horseradish peroxidase (1:2000; Santa Cruz Biotechnology, Inc.) as the secondary antibody for $1 \mathrm{~h}$. The antigen-antibody complexes were then detected with enhanced chemiluminescence reagent ${ }^{16}$ and visualised by the Lumi-Imager using Lumi Analyst version 3.10 software (Roche Molecular Biochemicals).

\section{Statistical analysis}

Data are reported as mean values with their standard errors. Significance of differences between group means was determined by one-way ANOVA. 


\section{Results}

Role of insulin-like growth factor 1 receptor in mediating the proliferative effects of genistein in human breast cancer (MCF-7) cells

Genistein and $E_{2}$ have proliferative effects on human breast cancer (MCF-7) cells. Their proliferative effects could be completely abolished by co-incubation of MCF-7 cells with IGF-1 receptor antagonist JB-1 (Fig. 1). As JB-1 is a selective competitive antagonist of IGF-1 receptor autophosphorylation, the inhibition of the action of $\mathrm{E}_{2}$ and genistein by JB-1 suggests that IGF-1 receptor plays a pivotal role in mediating the proliferative effects of both $\mathrm{E}_{2}$ and genistein in human breast cancer (MCF-7) cells.

\section{Effect of genistein on insulin-like growth factor 1 receptor} promoter activity

Our previous study clearly shows that IGF-1 receptor expression is increased upon treatment with a physiological concentration of genistein in a time-dependent manner ${ }^{12}$. To determine if the increase in IGF-1 receptor expression by genistein was mediated by the up regulation of IGF-1 receptor promoter activities, a transient transfection assay was performed. MCF-7 cells were transiently transfected with IGF-1 receptor luciferase promoter $\mathrm{p}(2350 /+640)$ Luc or promoterless luciferase construct for $5 \mathrm{~h}$, followed by treatment with genistein $\left(10^{-6} \mathrm{M}\right)$ or $\mathrm{E}_{2}\left(10^{-8} \mathrm{M}\right)$ for another $24 \mathrm{~h}$. As shown in Fig. 2, genistein and $\mathrm{E}_{2}$ significantly increased the IGF-1 receptor promoter luciferase activity and their induction could be abolished by co-treatment with the anti-oestrogen ICI 182,780. There was no luciferase activity detected in the cells that were transfected with promoterless luciferase construct (data not shown). These results suggest that genistein and $E_{2}$ could directly up regulate IGF-1 receptor gene expression by their stimulatory actions on IGF-1 receptor promoter activities, and it appears that these effects are also ER-dependent.

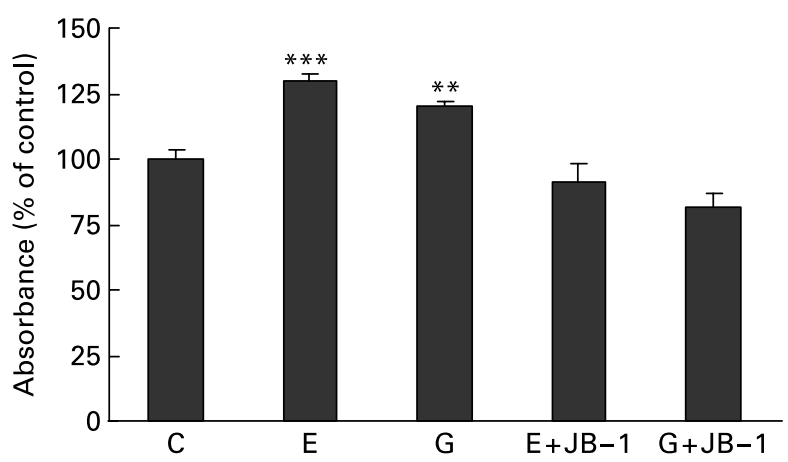

Fig. 1. Effect of genistein on cell proliferation in human breast cancer (MCF-7) cells. MCF-7 cells were cultured and treated with either $10^{-6} \mathrm{M}$-genistein $(\mathrm{G})$ or $10^{-8} \mathrm{M}-17 \beta$-oestradiol $(\mathrm{E})$ in the presence or absence of JB-1 $(1 \mu \mathrm{g} / \mathrm{ml})$ for $48 \mathrm{~h}$, and then cell number was determined by the $3-[4$, 5-dimethylthiazol 2-yl] 2, 5-diphenyltetrazolium bromide assay. Values are means for four independent experiments, with standard errors represented by vertical bars. Mean value was significantly different from that for control (C): ${ }^{\star \star} P<0.01,{ }^{\star \star \star} P<0.001$
Effect of JB-1 on insulin-like growth factor 1 receptor gene expression induced by genistein

To determine if functional IGF-1 receptor was required for genistein up regulation of IGF-1 receptor gene expression, MCF-7 cells treated with either genistein or $\mathrm{E}_{2}$ were co-incubated with or without the IGF-1 receptor antagonist JB-1. The up regulation of IGF-1 receptor gene expression induced by genistein was completely abolished by JB-1 (Fig. 3), indicating that the stimulatory effect of genistein on IGF-1 receptor expression not only required the ER-dependent pathway but also involved the activity of functional IGF-1 receptor. The action of genistein on IGF-1 receptor was similar to those of $E_{2}$, as JB-1 could also abolish the up regulation of IGF-1 receptor gene expression induced by $\mathrm{E}_{2}$ (Fig. 4).

Up regulation of insulin-like growth factor 1 receptor expression by genistein requires oestrogen receptor and de novo protein synthesis

Our previous results clearly show that genistein and $\mathrm{E}_{2}$ could increase the gene and protein expression of IGF-1 receptor and these effects could be completely blocked by the anti-oestrogen ICI $182,780^{12}$. To further investigate the potential mechanism involved in the up regulation of IGF1 receptor expression by genistein, MCF-7 cells treated with either genistein or $\mathrm{E}_{2}$ were co-incubated with or without CHX $(5 \mu \mathrm{g} / \mathrm{ml})$, a de novo protein synthesis inhibitor. The expression of IGF-1 receptor induced by $\mathrm{E}_{2}$ was completely blocked by $\mathrm{CHX}$ at both protein and mRNA level (Figs. 4 (A) and (B)), indicating that de novo protein synthesis is required for the action of $E_{2}$. Similar to the action of $\mathrm{E}_{2}$, the up regulation of IGF-1 receptor protein and mRNA by genistein could be blocked by $\mathrm{CHX}$ treatment (Figs. 4 (A) and (B)) and thus requires de novo protein synthesis.

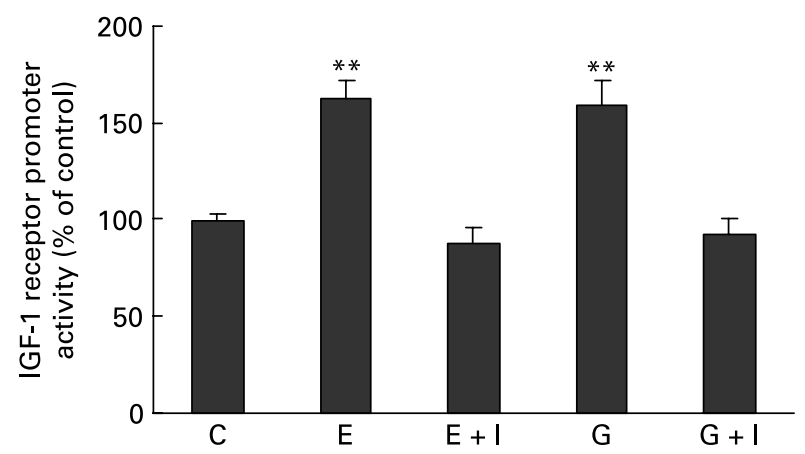

Fig. 2. Insulin-like growth factor (IGF)-1 receptor promoter luciferase assay. MCF-7 cells were cultured and treated with $10^{-6} \mathrm{M}$-genistein $(\mathrm{G})$ or $10^{-8} \mathrm{M}-17 \beta$-oestradiol $(\mathrm{E})$ in the presence and absence of $10^{-6} \mathrm{M}-\mathrm{ICI} 182,780$ (I) for $24 \mathrm{~h}$. Activities of luciferases encoded by experimental and internal control plasmid were measured sequentially with the Dual-Luciferase Reporter assay reagents. The IGF-1 receptor promoter firefly luciferase activities were normalised with $\mathrm{pRL}-\mathrm{TK}$ renilla luciferase values. The IGF-1 receptor promoter luciferase activity of control (C) was defined as $100 \%$. Values are means for three independent experiments, with standard errors represented by vertical bars. ${ }^{* \star}$ Mean value was significantly different from that for control $(P<0.01)$. 
IGF-1 receptor

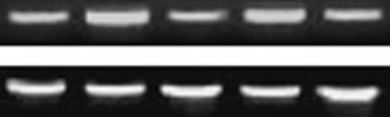

GAPDH

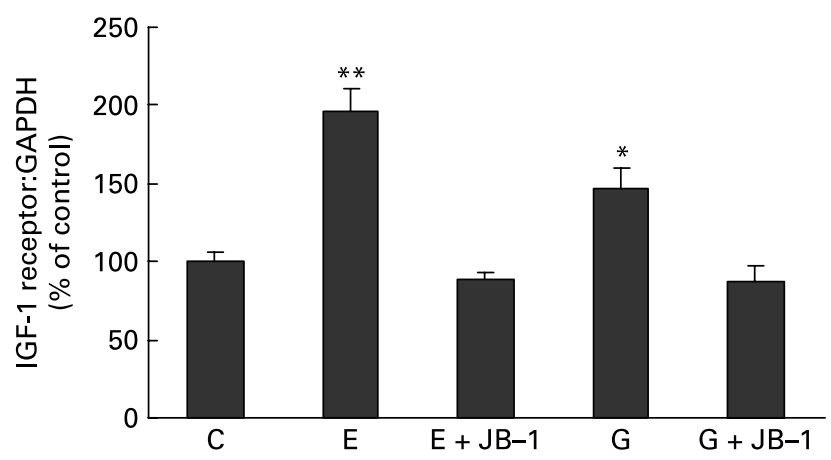

Fig. 3. Effect of JB-1 on insulin-like growth factor (IGF)-1 receptor gene expression induced by genistein in human breast cancer (MCF-7) cells. MCF-7 cells were cultured and treated with either $10^{-6} \mathrm{M}$-genistein $(\mathrm{G})$ or $10^{-8} \mathrm{M}-17 \beta$-oestradiol $(E)$ in the presence or absence of JB-1 $(1 \mu \mathrm{g} / \mathrm{ml})$ for $48 \mathrm{~h}$. Total RNA was isolated and IGF-1 receptor and glyceraldehyde-3-phosphate dehydrogenase (GAPDH) mRNA expressions were subjected to semiquantitative RT-PCR analysis. The mRNA expression level was expressed as a ratio to the expression of GAPDH. Values are means for three independent experiments, with standard errors represented by vertical bars. Mean value was significantly different from that for control $(C):{ }^{\star} P<0.05$, ${ }^{\star \star} P<0.01$.

\section{Discussion}

Genistein, a planar molecule with an aromatic A ring, has a chemical structure similar to that of steroidal oestrogens, and its ability to behave as an oestrogen in various tissues has been widely described. Our previous studies have shown that genistein has biphasic effects on the growth of the ERpositive human breast cancer (MCF-7) cells, in which high concentration $\left(>10^{-5} \mathrm{M}\right)$ inhibits ${ }^{17}$ while low concentration $\left(10^{-6} \mathrm{M}\right)$ stimulates breast cancer cell proliferation ${ }^{12}$. Our previous study clearly demonstrates that genistein has oestrogenlike activities and exerts its action via the activation of the IGF-1 receptor signalling pathway in human breast cancer MCF-7 cells ${ }^{12}$. In the present study, we provide further evidence that the IGF-1 receptor antagonist JB-1 can completely block the stimulatory effect of genistein on MCF-7 cells. Genistein can activate the transcription of IGF-1 receptor via ER. The stimulation of IGF-1 receptor expression by genistein appears to be related to the cross-talk of the ER pathway and the IGF-1 receptor pathway as well as de novo protein synthesis.

The IGF-1 receptor is a receptor-tyrosine kinase that plays a critical role in signalling, cell survival and proliferation. The IGF-1 receptor is necessary for normal breast biology, but recent clinical and experimental data strongly suggest that the same receptors are involved in the development of breast cancer $^{18}$. The IGF-1 receptor is over-expressed in the ER-positive breast cancer cells compared with its levels in normal epithelial cells. Studies clearly demonstrate the presence of independent but interacting mitogenic pathways in the ER-positive breast cancer cells, including the ER pathway and the IGF-1 receptor pathway ${ }^{9}$. In the present study, we used JB-1, a peptide

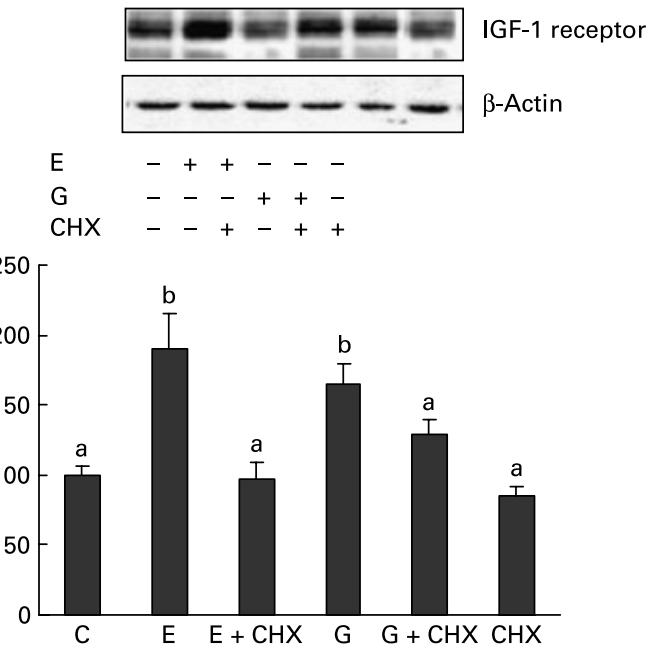

(B)

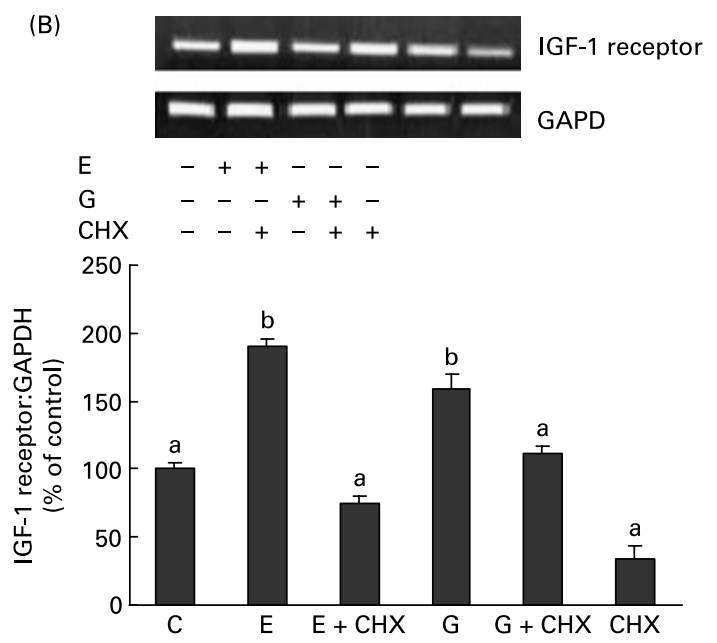

Fig. 4. Effect of cycloheximide ( $\mathrm{CHX})$ on the regulation of insulin-like growth factor (IGF)-1 receptor expression by genistein or $17 \beta$-oestradiol. MCF-7 cells were cultured and treated with $10^{-6} \mathrm{M}$-genistein $(G)$ or $10^{-8} \mathrm{M}$ - $17 \beta$-oestradiol $(\mathrm{E})$ in the presence or absence of $10^{-6} \mathrm{M}-\mathrm{CHX}$ for $48 \mathrm{~h}$. (A) IGF-1 receptor and $\beta$-actin protein expression. (B) Semi-quantitative RT-PCR analysis of IGF-1 receptor and glyceraldehyde-3-phosphate dehydrogenase (GAPDH) mRNA expression. Values are means for three independent experiments, with standard errors represented by vertical bars. Mean values with unlike letters were significantly different $(P<0.05)$.

analogue of IGF-1 that is involved in binding to the IGF-1 receptor. It is a potent, highly selective, competitive antagonist of IGF-1 receptor autophosphorylation and cellular proliferation. The present results clearly demonstrate the proliferative actions and the stimulatory effects on IGF-1 receptor induced by genistein and oestrogen could be completely blocked by co-treatment with JB-1. These findings suggest that IGF-1 receptor activation is necessary for the stimulatory effects of genistein and oestrogen in human breast cancer cells.

The IGF-1 and ER systems are engaged in a powerful functional cross-talk in human tissues. $\mathrm{E}_{2}$ and IGF-1 act together to stimulate proliferation in normal mammary epithelium and increase the risk of breast cancer ${ }^{19}$. IGF-1 may activate ER in the absence of estrogens in different cell types ${ }^{11,20}$. IGF-1 can modulate oestrogen action by acting via the tyrosine kinase of the IGF-1 receptor. Ligands for IGF-1 receptor can regulate 
ER gene expression and ER-mediated transcription in an oestrogen-independent manner ${ }^{21}$. In turn, oestrogen can activate the IGF-1 receptor signalling pathway at different levels. At the cell surface, oestrogen induces ER and IGF-1 receptor association, probably through an adapter protein and increases IGF-1 receptor phosphorylation ${ }^{22}$. Accumulating evidence indicates that the oestrogen-responsive region in the IGF-1 receptor promoter was mapped to a guanine-cytosine (GC)-rich sequence located between nucleotides -40 and -188 in the $5^{\prime}$ flanking region. A recent study reported that the effect of $\mathrm{E}_{2}$ on IGF-1 receptor expression was at least partly mediated through the activation of the Sp1 transcription factor in breast cancer cells ${ }^{23}$.

Genistein can mimic oestrogen to stimulate ER-positive cell proliferation. Our previous study clearly showed that genistein mimicked $E_{2}$ in stimulating the IGF-1 receptor signalling pathway and the effect was ER-dependent. The present study clearly further demonstrates the involvement of the cross-talk between ER and the IGF-1 receptor-dependent signalling pathway in mediating the actions of genistein in MCF-7 cells. Genistein not only increases the protein and mRNA expression of the IGF-1 receptor but also increases IGF-1 receptor promoter activity. These effects could be completely abolished by co-treatment of MCF-7 cells with ICI 180,782. These results clearly suggest that an increase in IGF-1 receptor transcription at least in part accounts for the induction of IGF-1 receptor expression by genistein and the effect is ER-dependent.

The present study also further determines the potential mechanism involved in the up regulation of IGF-1 receptor expression by genistein. CHX, a de novo protein synthesis inhibitor, can completely abolish the up regulation of IGF-1 receptor expression at both protein and mRNA level. In the case of protein expression, it is clearly shown that blocking new protein synthesis can prevent the translation of IGF-1 receptor mRNA into protein. As for the case of IGF-1 receptor mRNA expression, these results suggest that some labile proteins (with short half-lives in vivo) could be essential for the genistein activation of IGF-1 receptor transcription. Inhibition of new protein synthesis will prevent these labile proteins from being synthesised. Examples of these proteins could be proteins involved in the transcription machinery (coactivator and co-repressor).

In summary, the present data provide the first evidence that genistein activates the transcription of IGF-1 receptor gene expression. The stimulation of IGF-1 receptor expression by genistein appears to require the association of ER and IGF1 receptor as well as de novo protein synthesis. Most importantly, the present study provides the mechanistic basis to understand how genistein mimics oestrogen by activating ER-IGF-1 receptor cross-talk to stimulate human breast cancer cell growth. Thus, pre- and post-menopausal women who are at risk of developing ER-positive breast cancer should be cautioned when considering using genistein as an alternative approach to manage menopause-related syndromes.

\section{Acknowledgements}

We thank Dr Derek LeRoith for the IGF-1 receptor promoter construct. The present study was supported by the Areas of
Excellence Scheme established under the University Grants Committee of the Hong Kong Special Administrative Region, China (AOE/P-10/01), the Central Research Fund from The Hong Kong Polytechnic University (GU-135) and the National Natural Science Foundation of China (30570573).

\section{References}

1. Makiewicz L, Garey J, Adlercreutz H \& Gurpide E (1993) In vitro bioassays of non-steroidal phytoestrogens. J Steriod Biochem Mol Biol 45, 399-405.

2. Ju YH, Allred CD, Allred KF, Karko KL, Doerge DR \& Helferich WG (2001) Physiological concentrations of dietary genistein dose-dependently stimulate growth of estrogen-dependent human breast cancer (MCF-7) tumors implanted in athymic nude mice. J Nutr 131, 2957-2962.

3. Hsieh CY, Santell RC, Haslam SZ \& Helferich WG (1998) Estrogenic effects of genistein on the growth of estrogen receptor-positive human breast cancer (MCF-7) cells in vitro and in vivo. Cancer Res 58, 3833-3838.

4. Dees C, Foster JS, Ahamed S \& Wimalasena J (1997) Dietary estrogens stimulate human breast cells to enter the cell cycle. Environ Health Perspect 105, Suppl. 3, 633-666.

5. Ju YH, Allred KF, Allred CD \& Helferich WG (2006) Genistein stimulates growth of human breast cancer cells in a novel, postmenopausal animal model, with low plasma estradiol concentrations. Carcinogenesis 27, 1292-1299.

6. Allred CD, Allred KF, Ju YH, Clausen LM, Doerge DR, Schantz SL, Korol D, Wallig MA \& Helferich WG (2004) Dietary genistein results in larger MNU-induced, estrogendependent mammary tumors following ovariectomy of Sprague-Dawley rats. Carcinogenesis 25, 211-218.

7. Jorgensen M, Vendelbo B, Skakkebaek NE \& Leffers H (2000) Assaying estrogenicity by quantitating the expression levels of endogenous estrogen-regulated genes. Environ Health Perspect 108, 403-412.

8. Miodini P, Fioravanti L, Di Fronzo G \& Cappelletti V (1999) The two phyto-oestrogens genistein and quercetin exert different effects on oestrogen receptor function. $\mathrm{Br} J$ Cancer $\mathbf{8 0}$, 1150-1155.

9. Kato S, Masuhiro Y, Watamabe M, Kobayashi Y, Takeyama KI, Endoh H, Takeyama KI, Endoh H \& Yanagisawa J (2000) Molecular mechanism of a cross-talk between oestrogen and growth factor signaling pathways. Genes Cells 5, 593-601.

10. Lee AV, Jackson JG, Gooch JL, Hilsenbeck SG, CoronadoHeinsohn E, Osborne CK \& Yee D (1999) Enhancement of insulin-like growth factor signaling in human breast cancer: estrogen regulation of insulin receptor substrate-1 expression in vitro and in vivo. Mol Endocrinol 13, 787-796.

11. Surmacz E \& Bartucci M (2004) Role of estrogen receptor $\alpha$ in modulating IGF-I receptor signaling and function in breast cancer. J Exp Clin Cancer Res 23, 385-394.

12. Chen WF \& Wong MS (2004) Genistein enhances insulin-like growth factor signaling pathway in human breast cancer (MCF-7) cells. J Clin Endocrinol Metab 89, 2351-2359.

13. Denizot F \& Kang R (1986) Rapid colorimetric assay for cell growth and survival. Modifications to the tetrazolium dye procedure giving improved sensitivity and reliability. J Immunol Methods 89, 271-277.

14. Bradford MM (1976) A rapid and sensitive method for the quantitation of microgram quantities of protein utilizing the principle of protein-dye binding. Anal Biochem 72, 248-252.

15. Sriussadaporn S, Wong MS, Pike WJ \& Favus MJ (1995) Tissue specificity and mechanism of vitamin D receptor up-regulation during dietary phosphorus restriction in the rat. $J$ Bone Miner Res 10, 271-280. 
16. Mattson DL \& Bellehumeur TG (1996) Comparison of three chemiluminescent horseradish peroxidase substrates for immunoblotting. Anal Biochem 240, 306-308.

17. Chen WF, Huang MH, Tzang CH, Yang M \& Wong MS (2003) Inhibitory actions of genistein in human breast cancer (MCF-7) cells. Biochim Biophys Acta 1683, 187-196.

18. Surmacz E (2000) Function of the IGF-I receptor in breast cancer. J Mammary Gland Biol Neoplasia 5, 95-105.

19. Martin MB \& Stoica A (2002) Insulin-like growth factor-I and estrogen interactions in breast cancer. $J$ Nutr 132, 3799S-3801S.

20. Agrati P, Garnier M, Patrone C, Pollio G, Santagati S, Vegeto E \& Maggi A (1997) SK-ER3 neuroblastoma cells as a model for the study of estrogen influence on neural cells. Brain Res Bull 44, 519-523.

21. Lee AV, Weng CN, Jackson JG \& Yee D (1997) Activation of estrogen receptor-mediated gene transcription by IGF-I in human breast cancer cells. J Endocrinol 152, 39-47.

22. Mendez P, Azcoitia I \& Garcia-Segura LM (2005) Interdependence of oestrogen and insulin-like growth factor-I in the brain: potential for analysing neuroprotective mechanisms. $J$ Endocrinol 185, 11-17.

23. Maor S, Mayer D, Yarden RI, Lee AV, Sarfstein R, Werner H \& Papa MZ (2006) Estrogen receptor regulates insulin-like growth factor-I receptor gene expression in breast tumor cells: involvement of transcription factor Sp1. J Endocrinol 191, 605-612. 